\title{
The Epidemiology, Therapeutic Patterns, Outcome, and Challenges in Managing Septic Shock in a Sub-Saharan African Intensive Care Unit: A Cross- Sectional Study
}

\author{
Junette Arlette Metogo Mbengono ${ }^{1,2,3}$, Joël Noutakdie Tochie ${ }^{1 *}$, Ferdinand Ndom Ntock ${ }^{1}$, Yves Bertrand \\ Nzouango ${ }^{1}$, Stephane Kona ${ }^{1}$, Glwadys Ngono Ateba ${ }^{1}$, Cassandra Tocko ${ }^{3}$, Aminata Colibaly ${ }^{3}$, Gérard \\ Beyiha $^{1,2,3}$, Jacqueline Ze Minkande ${ }^{1,4}$
}

\author{
${ }^{1}$ Department of Anesthesiology and Critical Care, Faculty of Medicine and Biomedical Sciences, University of \\ Yaoundé I, Yaoundé, Cameroon \\ ${ }^{2}$ Faculty of Medicine and Pharmaceutical Sciences, University of Douala, Douala, Cameroon \\ ${ }^{3}$ Department of Emergency Medicine, Anesthesiology and Critical Care, Douala General Hospital, Douala, \\ Cameroon \\ ${ }^{4}$ Department of Anesthesiology and Critical Care, Gynaeco-Obstetrics and Paediatric Hospital, Yaoundé, Cameroon
}

*Corresponding Author: Joël Nouktadie Tochie, M.D., Faculty of Medicine and Biomedical sciences, University of Yaoundé 1, Yaoundé, Cameroon. Tel: +237-676558825, Email: joeltochie@gmail.com

Received July 20, 2019; Accepted October 19, 2019; Online Published November 5, 2019

\begin{abstract}
Background: Septic shock (SS) is a health priority in sub-Saharan Africa. However, there is a dearth of data in this regard. Objective: This study aimed to determine the epidemiology, therapeutic patterns, outcome, and challenges in managing SS in a tertiary intensive care unit (ICU) of sub-Saharan Africa.

Methods: The hospital files of 36 consecutive patients admitted to the ICU of the Douala General Hospital (DGH), Cameroon over the year 2018 were reviewed for SS. SS was diagnosed based on Sepsis-3 definition. Demographic and clinical characteristics, treatment details, and outcomes of patients with SS were reviewed. Data was analyzed using the chi-square or Fisher exact tests and Bonferroni correction.

Results: SS accounted for $36(9.4 \%)$ ICU admissions. The majority of patients were males $(63.9 \%)$. The most common site of infection was the lungs. The mean age, average mean arterial pressure (MAP), and mean sequential organ failure assessment (SOFA) score of patients were $52.9 \pm 25.2$ years, $52 \pm 18 \mathrm{~mm} \mathrm{Hg}$, and $9.2 \pm 2.3$, respectively. Noradrenaline was the sole vasopressor used. Therapeutic challenges included the inability to have a specific antibiogram before a mean duration of 7 days. The mortality rate was $39 \%$ and associated with age $\leq 1$ year, MAP $\leq 65 \mathrm{~mm} \mathrm{Hg}$, Glasgow Coma Score (GCS) $\leq 8$, and mechanical ventilation, which were not attenuated after Bonferroni correction.

Conclusion: SS is a frequent cause of ICU admission and is associated with a high mortality rate. SS mortality-related factors can be screened during SS management for more aggressive ICU management geared at preventing death.

Keywords: Septic, Shock, Epidemiology, Intensive Care, Sub-Saharan Africa
\end{abstract}

\section{Background}

Sepsis and septic shock (SS) are globally recognized by the WHO as health priorities. ${ }^{1}$ Patients with SS have an inadequate blood supply perfused to noble organs, resulting in coma, strokes, myocardial infarction, acute kidney injury, or multi-organ dysfunction and ultimately death if resuscitation is not performed in a timely manner. ${ }^{2,3}$ Survivors of SS are at an increased risk of reduced quality of life due to long-term physical, cognitive, and psychological dysfunction, ${ }^{4,5}$ as well as death within a year following hospital discharge. ${ }^{6}$ Worldwide, the incidence of sepsis is estimated to be 188 to 270 per 100000 adults $^{7,8}$ and 19.4 million children are hospitalized for sepsis each year. ${ }^{8}$ SS accounts for a mortality rate varying between $17.1 \%$ and $60.1 \%^{8-12}$ and 5.3 million child deaths per annum. ${ }^{8}$ Currently, the debate on the most effective pharmacological management for SS is ongoing. Immediate treatment with appropriate empirical or specific antibiotics, a focal point in curbing the burden of SS, remains challenging. ${ }^{8}$ About $70 \%-80 \%$ of sepsis cases are community-acquired, making

Copyright (C) 2019 The Author(s). This is an open-access article distributed under the terms of the Creative Commons Attribution License (http:// creativecommons.org/licenses/by/4.0), which permits unrestricted use, distribution, and reproduction in any medium, provided the original work is properly cited. 
primary care and emergency departments pivotal points to improving recognition and early management. However, when the infection is overwhelming, it often becomes a SS necessitating intensivists and intensive care unit (ICU) admission for optimal care.

The majority of the current data on SS is from ICUs in high-income countries. ${ }^{11,13}$ Although SS is common in resource-limited settings, there is limited contemporary data on the demographic and clinical characteristics, treatments, and outcomes of patients admitted for SS to ICUs in sub-Saharan Africa. Yet, this data is important to increase awareness of this life-threatening disease in sub-Saharan Africa, to highlight the need for continuous preventive interventions, and to help guide resource allocation. ${ }^{14}$

\section{Objective}

We aimed to determine the epidemiology, therapeutic profiles and outcomes of patients admitted for SS to a reference ICU in Cameroon.

\section{Methods}

\subsection{Study Design, Setting and Study Participants}

This retrospective cross-sectional study was conducted in the ICU of Douala General Hospital (DGH), Douala, Cameroon, between January 1, 2018 and December 31, 2018 (12 months). Data was collected during the month of March 2019. Douala, the economic capital of Cameroon, is the largest urban area in the country and has an estimated population of $2445945 .^{15}$ Its coastal location and good landscape have attracted several business settlements, making it one of the country's most populated cities with increasing healthcare needs. Douala has a total surface area of about $210 \mathrm{~km}^{2} .{ }^{16}$ The DGH is a tertiary care center and university teaching hospital in Douala. As a tertiary hospital, its ICU is one of the main referral ICUs for critically ill patients in Cameroon and its environs. Facilities for critical care management in this ICU comprise 20 beds, 5 ventilators, several laryngoscopes, several endotracheal tubes, 10 electric pump syringes, 6 multi-parameter monitoring machines, and a pharmacy containing emergency drugs such as adrenaline, noradrenaline, dobutamine, ephedrine, atropine. The unit is not constantly equipped with a blood gas machine for measuring serum lactate. The unit is run by 5 consultant intensive care physicians, 2 resident physicians in critical care medicine, 16 nurses, and 2 general practitioners.

\subsection{Sampling; Inclusion and Exclusion Criteria}

Assuming a 95\% confidence interval (CI), a variability of 1.96 , an accuracy of 0.05 , and a SS prevalence rate of $8.3 \%,{ }^{17}$ the Schulz and Grimes formula was used to obtain a minimum sample size of 30 patients with SS. By consecutive convenience sampling, the medical records of 383 patients admitted to the ICU of DGH in the year 2018 were studied. Among those files, 36 were of patients admitted for SS. Patients with cardiogenic, anaphylactic, or hypovolemic shock and those with mixed shock were excluded.

\subsection{Definition of Terms}

SS was diagnosed based on the sepsis-3 definition but for the exclusion of serum lactate; that is, signs of sepsis (sequential organ failure assessment [SOFA] score $\geq 2$ points), persistent hypotension despite adequate volume resuscitation, and requiring vasopressors to maintain a mean arterial blood pressure (MAP) $\geq 65 \mathrm{~mm} \mathrm{Hg.}{ }^{18}$ Defined as a risk factor was any attribute, characteristic, or exposure of an individual that increased the likelihood of developing a disease like SS.

\subsection{Data Collection}

Data was extracted from the hospital files onto a standardized data collection form and included:

1. Demographic data: age and gender

2. Clinical data: comorbidities, MAP, SOFA score, site of infection, and Glasgow Coma Score (GCS).

3. Treatment details: type of fluid and vasopressor used for resuscitation, empirical antibiotics used, need for escalation of antibiotics, specific antibiotics used after bacterial cultures, the germ isolated, and the need for mechanical ventilation.

4. Outcome: number of days of vasopressor therapy, number of days on mechanical ventilation, complications (cardiopulmonary arrest, acute kidney injury, hepatic failure, etc.), length of ICU stay, and inICU mortality rate.

5. Risk factors for SS-related mortality: age, gender, GCS, MAP, site of infection, use of mechanical ventilation in the treatment of SS, antibiotic therapy (monotherapy or combined antibiotic therapy), escalation of antibiotic therapy (yes or no), cardiopulmonary successfully managed during ICU stay (yes or no), hepatic failure (yes or no), and the SOFA score.

\subsection{Data Analysis}

The data was entered into Epi Info 3.5.1 software. All variables were distributed in the form of simple frequencies. Variables with excessive missing data precluding meaningful analyses were excluded. Factors associated with in-ICU mortality among SS patients were studied using the chi-square or Fisher exact test where appropriate. The original alpha-value was set at 0.05 . To reduce the chance of obtaining false-positive results from the multiple analyses performed on the same dependent variable, the Bonferroni adjusted $P$ value was calculated by dividing the alpha-value by the number of comparisons. Hence, any comparison was statistically significant if it was inferior to the Bonferroni adjusted $P$ value.

\section{Results}

SS accounted for 36 (9.4\%) ICU admissions out of a total of 383 admissions in the year 2018. Patients' mean age was $52.9 \pm 25.2$ years (range: $1-83$ years), and $63.9 \%$ were 
Table 1. Socio-demographic and Clinical Characteristics

\begin{tabular}{|c|c|c|}
\hline Variables & Frequency $(n=36)$ & $\%$ \\
\hline \multicolumn{3}{|l|}{ Age (y) } \\
\hline $1-25$ & 7 & 19.4 \\
\hline $26-45$ & 4 & 11.1 \\
\hline $46-65$ & 9 & 25 \\
\hline$\geq 65$ & 16 & 44.4 \\
\hline \multicolumn{3}{|l|}{ Gender } \\
\hline Male & 23 & 63.9 \\
\hline Female & 13 & 36.1 \\
\hline \multicolumn{3}{|l|}{ Co-morbidities } \\
\hline Hypertension & 15 & 41.5 \\
\hline Surgery within one week & 11 & 30.5 \\
\hline Diabetes & 6 & 16.7 \\
\hline Active cancer & 3 & 8.3 \\
\hline Chronic kidney disease & 3 & 8.3 \\
\hline Heart failure & 3 & 8.3 \\
\hline HIV/AIDS & 2 & 5.6 \\
\hline Stroke & 2 & 5.6 \\
\hline Asthma & 2 & 5.6 \\
\hline Mean arterial pressure & $52 \pm 18$ & \\
\hline Mean systolic BP & $71 \pm 22$ & \\
\hline Mean Diastolic BP & $42 \pm 16$ & \\
\hline Mean GCS & $9.1 \pm 4.3$ & \\
\hline Mean SOFA Score & $9.2 \pm 2.3$ & \\
\hline \multicolumn{3}{|l|}{ SOFA Score } \\
\hline $2-4$ & 24 & \\
\hline $5-7$ & 9 & \\
\hline$\geq 8$ & 3 & \\
\hline \multicolumn{3}{|l|}{ Origin of infection } \\
\hline Pulmonary & 17 & 45.7 \\
\hline Intra-abdominal & 11 & 31.4 \\
\hline Cutaneous & 4 & 11.4 \\
\hline Urinary & 4 & 11.4 \\
\hline \multicolumn{3}{|l|}{ Fluids for resuscitation } \\
\hline Normal saline & 34 & 97.1 \\
\hline Ringer lactate & 3 & 8.6 \\
\hline Geloplasma & 1 & 2.9 \\
\hline \multicolumn{3}{|l|}{ Empirical antibiotics used } \\
\hline Metronidazole & 17 & 48.6 \\
\hline Ceftriaxone & 16 & 45.7 \\
\hline Imipenem & 9 & 25.7 \\
\hline Amikacin & 8 & 22.9 \\
\hline Ofloxacin & 8 & 22.9 \\
\hline Gentamicin & 7 & 20 \\
\hline Amoxicillin-clavulanate & 4 & 11.4 \\
\hline Levofloxacin & 4 & 11.4 \\
\hline Trimethoprim/sulfamethoxazole & 2 & 5.7 \\
\hline Vancomycin & 1 & 2.9 \\
\hline Escalation of antibiotics used & 4 & 11.4 \\
\hline Ofloxacin & 2 & 2.9 \\
\hline Amikacin & 1 & 2.9 \\
\hline Imipenem & 1 & 2.9 \\
\hline Metronidazole & 1 & 2.9 \\
\hline Vancomycin & 1 & 2.9 \\
\hline Piperacillin/tazobactam & 1 & 2.9 \\
\hline
\end{tabular}

males. The main comorbidity was hypertension observed in $32(91.4 \%)$ patients (Table 1$)$. The mean GCS was $9.1 \pm 4.3$, and the mean SOFA score was $9.2 \pm 2.3$. The most common site of infection was the lungs (45.7\%) as demonstrated in Table 1. SS was hospital-acquired in $72 \%$ against $28 \%$ cases of community-acquired.

The main fluid used for resuscitation was normal saline (97.1\%), while noradrenaline was the sole vasopressor used (Table 1). Dobutamine, adrenaline, and dopamine were only used to compute the SOFA score and were not used for the management of SS. A combination of at least 2 antibiotics was seen in $32(91.4 \%)$ patients. The most used empirical antibiotics were metronidazole (48.6\%) and ceftriaxone (45.7\%) as shown in Table 1.

Bacterial cultures were collected from all participants, but a mean duration of 7 days was required to determine if a germ was present in the blood, urine, pus, central venous catheter, or urinary catheter bacterial culture samples. Just one patient had a positive bacterial culture after 7 days. The isolated germ was an Acinetobacter species from a central venous catheter. Fortunately, the germ was sensitive to the on-going empirical antibiotics already instituted (amikacin and imipenem). Blind (without bacterial culture) escalation of antibiotics was performed in $4(11.4 \%)$ patients. The most used antibiotic in this case was ofloxacin. Mechanical ventilation was required in $24(68.6 \%)$ patients. The mean duration of mechanical ventilation was $2.4 \pm 1.9$ days (range: $1-8$ days). The mean durations of vasopressor therapy and length of ICU stay were $2.6 \pm 2.2$ days (range: $1-11$ days) and $3.5 \pm 3.1$ days (range: 1-13 days), respectively. Fourteen (39\%) patients with SS had a fatal outcome. The risk factors for SS-related mortality which were not attenuated after Bonferroni adjustment were age $\leq 1$ year, a MAP $\leq 65 \mathrm{~mm} \mathrm{Hg}$, a GCS $\leq 8$, and the use of mechanical ventilation (Table 2 ).

\section{Discussion}

The current study aimed to determine the epidemiology, therapeutic patterns, outcomes, and challenges in the management of patients with SS admitted to a major referral ICU of Cameroon. The prevalence of SS was 9.4\%. Affected patients had a mean age of $52.9 \pm 25.2$ years, and $63.9 \%$ of them were males. The mean SOFA score was $9.2 \pm 2.3$ and the most common site of infection was the lungs. Noradrenaline was the sole vasopressor used. Therapeutic challenges included the inability to have a specific antibiogram before a mean duration of 7 days. The in-ICU mortality rate was $39 \%$ and was associated with an age $\leq 1$ year, a MAP $\leq 65 \mathrm{~mm} \mathrm{Hg}$, a GCS $\leq 8$, and the use of mechanical ventilation.

The prevalence of SS was found to be $9.4 \%$, lower than the $13.7 \%$ obtained in a French ICU by Quenot et al, ${ }^{19}$ probably explained by differences in the definition of SS. Quenot et $\mathrm{al}^{19}$ defined SS based on the PROWESSSHOCK study ${ }^{20}$ as a suspected or documented infection requiring initiation of vasopressors despite adequate vascular filling and with at least one of the following 
Table 2. Assessment of Risk Factors Associated With in-ICU Mortality in Septic Shock Patients

\begin{tabular}{|c|c|c|c|}
\hline Variable & $\begin{array}{c}\text { Alive } \\
(\mathrm{n}=\mathbf{2 2})\end{array}$ & $\begin{array}{c}\text { Death } \\
(n=14)\end{array}$ & $P$ Value \\
\hline \multicolumn{4}{|l|}{ Age $\leq 1$ years } \\
\hline Yes & 19 & 3 & \multirow[t]{2}{*}{$0.0002 *$} \\
\hline No & 3 & 11 & \\
\hline \multicolumn{4}{|l|}{ Age $\geq 65$ year } \\
\hline Yes & 19 & 11 & \multirow[t]{2}{*}{0.6582} \\
\hline No & 3 & 3 & \\
\hline \multicolumn{4}{|l|}{$\mathrm{MAP} \leq 65 \mathrm{~mm} \mathrm{Hg}$} \\
\hline Yes & 2 & 14 & \multirow[t]{2}{*}{$<0.0001^{*}$} \\
\hline No & 20 & 0 & \\
\hline \multicolumn{4}{|l|}{$\mathrm{GCS} \leq 8$} \\
\hline Yes & 2 & 14 & \multirow[t]{2}{*}{$<0.0001^{*}$} \\
\hline No & 20 & 0 & \\
\hline \multicolumn{4}{|l|}{ Origin of infection } \\
\hline Pulmonary & 2 & 14 & \multirow[t]{4}{*}{0.7845} \\
\hline Intra-abdominal & 1 & 10 & \\
\hline Cutaneous & 0 & 4 & \\
\hline Urinary & 0 & 4 & \\
\hline \multicolumn{4}{|c|}{ Mechanically ventilated } \\
\hline Yes & 0 & 13 & \multirow[t]{2}{*}{$<0.0001^{*}$} \\
\hline No & 22 & 1 & \\
\hline \multicolumn{4}{|l|}{ Antibiotic therapy } \\
\hline Monotherapy & 0 & 3 & \multirow[t]{2}{*}{0.0509} \\
\hline Combination & 22 & 11 & \\
\hline \multicolumn{4}{|c|}{ Escalation of antibiotics } \\
\hline Yes & 0 & 4 & \multirow[t]{2}{*}{0.01699} \\
\hline No & 22 & 10 & \\
\hline \multicolumn{4}{|c|}{ Cardiopulmonary arrest successfully managed } \\
\hline Yes & 0 & 4 & \multirow[t]{2}{*}{0.01699} \\
\hline No & 22 & 10 & \\
\hline \multicolumn{4}{|l|}{ Hepatic failure } \\
\hline Yes & 0 & 1 & \multirow[t]{2}{*}{0.3889} \\
\hline No & 22 & 13 & \\
\hline \multicolumn{4}{|l|}{ SOFA score } \\
\hline $2-4$ & 2 & 9 & \multirow[t]{3}{*}{0.8889} \\
\hline $5-7$ & 1 & 4 & \\
\hline$\geq 8$ & 0 & 1 & \\
\hline
\end{tabular}

GCS: Glasgow coma scale; qSOFA: quick Sequential Organ Failure Assessment; MAP: Mean arterial pressure

*Bonferroni corrected $P$ value $<0.0045$.

hypoperfusion criteria: metabolic acidosis; oliguria/renal failure; or hepatic dysfunction. Contrary to Quenot et al, SS was defined in the current study in conformity with the Sepsis-3 definition, ${ }^{18}$ but for the exclusion of serum lactate (due to our resource-limited setting). The mean patients' age was $52.9 \pm 25.2$ years, and there was a predominance of males, concurring with the results of Boussekey et al and Quenot el al in France ${ }^{19,21}$ and Balcan ${ }^{2}$ in Turkey. The predominance of an increasing aging population in the current series was correlated with the frequencies of comorbidities, like diabetes, which are factors associated with SS. The mean SOFA score in the present study was $9.2 \pm 2.3$, similar to the $9.16 \pm 3.16^{2}, 10.9 \pm 3.2{ }^{19}$ and $11^{21}$ obtained in Turkey and France, respectively. Previous studies have shown that a decreased SOFA score is known to be predictive of decreased mortality, while an increased SOFA score is indicative of increased mortality. ${ }^{2,23}$ In contrast, an increase in SOFA score was not found to be associated with mortality in the present study. The majority of SS cases were hospital-acquired, corroborating with the results of Baharoon et al on the epidemiology of sepsis in an tertiary ICU of Saudi Arabia. ${ }^{22}$

Similarly to Baharoon et al in Saudi Arabia, ${ }^{22}$ the main comorbidities were hypertension followed by diabetes. Also, like previous reports, ${ }^{11,12,19,21}$ the most common sites of infection responsible for SS were the lungs followed by the abdomen.

The mean duration of ICU stay was $3.5 \pm 3.1$ days, drastically lower than the $8.44 \pm 11.61$ days observed in Turkey. ${ }^{2}$ This may reflect the differences in the health infrastructure and equipment between the Turkish and Cameroonian health systems, with better management of this pathology in Turkey and more Turkish SS patients living longer. It may also reflect more virulent bacteria in the hospital ecology responsible for shorter hospital stays and a higher in-ICU mortality rate in the milieu of the current study compared with Turkey. The in-ICU mortality rate in the current study was 39\%. This rate concurred with the fatality rates varying between $25.8 \%$ and $60.1 \%$ reported in the literature. ${ }^{11,12,21,24,25}$ The mortality rate in the present study (39\%), however, remains high and may be attributable to late ICU admissions with resultant delayed resuscitative measures on the one hand and by an elderly study population with several co-morbidities (like diabetes) which may adversely affect the course of SS.

After controlling for false-positive results, 4 SS-related mortality risk factors were identified: being aged $\leq 1$ year, having a MAP $\leq 65 \mathrm{~mm} \mathrm{Hg}$, having a GCS $\leq 8$, and being mechanically ventilated. The current findings confirm the common risk factors associated with mortality in the literature. ${ }^{2,11,21}$ In contrast to a French study ${ }^{21}$ and a multinational study ${ }^{11}$ which found older age (age $\geq 65$ years) to be a significant risk factor for SS-related mortality, it was observed in this study that being an infant was instead a risk factor, probably explained by the immature immunity of infants. ${ }^{26}$ Similar to previous studies, ${ }^{27-29}$ a low GCS was found in this study to be associated with mortality in patients with SS. It is noteworthy that a low GCS is also a reliable indicator of sepsis through the SOFA or quick SOFA score assessment. ${ }^{18,27}$ Eidelman et $\mathrm{al}^{29}$ found that SS patients with a GCS of 15,14 to 13,12 to 9 , or 8 to 3 had mortality rates of $16 \%, 20 \%, 50 \%$, and $63 \%$, respectively. However, the various levels of GCS and associated mortality in the current series were not stratified. All patients admitted with a GCS $\leq 8$ had a fatal outcome ( $100 \%$ mortality rate), perhaps as a result of septic encephalopathy. ${ }^{29}$ The sepsis-3 consensus ${ }^{18}$ and the Surviving Sepsis Campaign ${ }^{30}$ recommend targeting a MAP $\geq 65 \mathrm{~mm} \mathrm{Hg}$ during initial resuscitation of patients with SS to maintain blood perfusion to noble organs such as the brain, kidneys, heart, and liver. ${ }^{31}$ However, this MAP target should be increased to more than $75 \mathrm{~mm} \mathrm{Hg}$ in SS 
patients with hypertension (to prevent cerebral ischemia or strokes) as a result of a rightward shift in cerebral pressureflow autoregulation caused by chronic hypertension or atherosclerosis. ${ }^{32}$ In the present study, hypertension was the main comorbidity (41.5\%), and the average MAP was 52 $\mathrm{mm} \mathrm{Hg}$ on admission. This may imply that the majority of patients already had cerebral ischemia and other end-organ damage on admission due to severe organ hypoperfusion, thus explaining why a MAP $\leq 65 \mathrm{~mm} \mathrm{Hg}$ on admission was predictive of mortality. Similar to previous reports, ${ }^{2,11,21}$ mechanical ventilation was observed to be associated with SS-related mortality in the current study. This may be explained by the fact that multidrug-resistant germs are likely to grow in the mechanical ventilator device, thereby increasing mortality. ${ }^{33}$ Moreover, given that the mean length of ICU stay was more than 2 days (precisely, 3.5 days; range: 1-13 days), it is possible that some mechanically ventilated patients acquired nosocomial infections such as ventilator-associated pneumonia, ${ }^{34}$ thereby increasing their risk of mortality. Furthermore, in the year 2018, several ventilators in the study setting had a problem with the air system humidification, predisposing ventilated patients to an increased risk of mortality from hypoxia due to mucus plug formation in the endotracheal tube. In contrast to Boussekey et al, ${ }^{21}$ Sakr et al, ${ }^{11}$ and Quenot et al, ${ }^{19}$ comorbidities and a high SOFA score were not found to be risk factors for mortality in the current study, probably explained by the small sample size.

Quenot et al in France observed that the rate of documented germs in SS patients admitted to the ICU varied from $52 \%$ to $90 \%,{ }^{19}$ while in the current study, only one microorganism (2.7\%), Acinetobacter, could be identified. Early and specific antibiotic therapy improves the prognosis of patients suffering from SS. ${ }^{21,35,36}$ Obtaining a specific antibiogram was a major challenge in the current study, as a mean duration of 7 days was necessary to rule in or out the presence of a germ through bacterial culture analyses. In the current study, empirical antibiotic therapy was initiated in all patients on admission, and blind (without microscopy, culture, and sensitivity) escalation of antibiotics was performed in 4 (11.4\%) patients who had worsening clinical conditions. Regarding the hemodynamic support for SS, noradrenaline was the sole vasopressor used in the current study. This clinical practice re-iterates the consensus stipulating that noradrenaline is the most effective vasopressor in the management of SS. ${ }^{37}$

Some limitations of the current study must be acknowledged. Firstly, it is retrospective design and the relatively small number of patients $(n=36)$ implies cautious generalization of the findings. Secondly, the cross-sectional design makes it impossible to infer causality or untangle bi-directional relationships. Thirdly, the unavailability of serum lactate in the current series to add more diagnostic arguments for the case definition of SS makes it difficult to conclude that all 36 participants had SS. Serum lactate is a marker of tissue hypoxia ${ }^{38}$ and a predictor of mortality in septic patients. ${ }^{39}$ Several recent studies ${ }^{40,41}$ evaluating the
Sepsis-3 definition have shown that it is possible to have SS without the lactic acidosis requirements of the Sepsis-3 definition. Hence, the definition in this study, adapted from the Sepsis-3 consensus, is partially justified. Furthermore, the unavailability of other potent vasopressors such as terlipressin which have proven their efficacy in reducing the mortality rate of SS patients when it is associated with noradrenaline is deplorable. ${ }^{42}$ Lastly, chronic alcoholism, a previously established risk factor for SS mortality ${ }^{43,44}$ due to hepatic failure, could not be studied in the current series due to the retrospective design of the study and lack of data on alcohol consumption.

The strengths of the present study include a homogeneous population comprising only patients with SS and not a mixture of sepsis, SS, and other types of shocks as in many published studies.

\section{Conclusion}

The current findings suggest that SS accounts for about one out of every 10 admissions and one out of every 3 deaths among patients admitted for SS in the ICU in this study. Affected patients had a relatively advanced age, were predominantly males, and mainly had pulmonary infections. Risk factors associated with mortality in SS patients were being aged $\leq 1$ year, having a MAP $\leq 65 \mathrm{~mm}$ $\mathrm{Hg}$, having a GCS $\leq 8$, and the use of mechanical ventilation on admission. These risk factors can immediately be screened on ICU admission in order to identify SS patients requiring prompt and aggressive resuscitation measures geared at preventing their deaths. There is an urgent need to revamp the laboratory in the study site with antibiogram culture media able to rule in or out a germ within a maximum duration of 48 hours for the institution of a specific antibiotic therapy geared to a life-saving purpose.

\section{Research Highlights}

\section{What Is Already Known?}

Globally, SS is recognized as a health priority by the WHO due to its high morbidity and mortality, particularly in critically ill patients. With limited contemporary data on SS in sub-Saharan Africa, this study aimed to determine the epidemiology, therapeutic patterns, prognosis (mortality rate and its risk factors), and challenges in the management of patients admitted for SS in a major referral ICU of Cameroon.

\section{What This Study Adds?}

The prevalence of SS found in this study was $9.4 \%$. The inability to have a specific antiobiogram before 7 days was the greatest challenge to treatment. The mortality rate of $39 \%$ was associated with aged $\leq 1$ years, MAP $\leq 65 \mathrm{~mm}$ $\mathrm{Hg}, \mathrm{GCS} \leq 8$, and mechanical ventilation. Overall, there is an urgent need for the timely provision of antibiograms to institute a specific antibiotic therapy geared toward saving lives. 


\section{Conflict of Interest Disclosures}

The authors declare that they have no competing interests.

\section{Ethical Approval}

Ethical approval was obtained from the Research Ethics Committee of the Douala General Hospital, Douala, Cameroon under the ethical clearance $N^{\circ}$ 289/RECDGH/ $\mathrm{DM} / 2019$.

\section{Authors' Contributions}

JAMM and JNT: Study conception and design, acquisition of data, data analysis and interpretation, manuscript writing and critical revisions. FNN, YBN, SK, GNA, CT and AC: acquisition of data and critical revisions. JAMM, GB and JZM: critical revision of the manuscript for intellectual content. All authors read and approved the final manuscript.

\section{Acknowledgments}

The authors thank all patients who took part in this study and all staff members of the participating hospitals for their commitment to patient care.

\section{References}

1. Reinhart K, Daniels R, Kissoon N, Machado FR, Schachter RD, Finfer S. Recognizing sepsis as a global health priority--a WHO resolution. N Engl J Med. 2017;377(5):414-417. doi:10.1056/ NEJMp1707170.

2. Balcan B, Olgun Ş, Torlak F, Sağmen SB, Eryüksel E, Karakurt $\mathrm{S}$. Determination of factors affecting mortality of patients with sepsis in a tertiary intensive care unit. Turk Thorac J. 2015;16(3):128-132. doi:10.5152/ttd.2015.4510.

3. Cohen J. The immunopathogenesis of sepsis. Nature. 2002;420(6917):885-891. doi:10.1038/nature01326.

4. Yende S, Austin S, Rhodes A, et al. Long-term quality of life among survivors of severe sepsis: analyses of two international trials. Crit Care Med. 2016;44(8):1461-1467. doi:10.1097/ ccm.0000000000001658.

5. Iwashyna TJ, Ely EW, Smith DM, Langa KM. Long-term cognitive impairment and functional disability among survivors of severe sepsis. Jama. 2010;304(16):1787-1794. doi:10.1001/ jama.2010.1553.

6. Prescott HC, Osterholzer JJ, Langa KM, Angus DC, Iwashyna TJ. Late mortality after sepsis: propensity matched cohort study. BMJ. 2016;353:i2375. doi:10.1136/bmj.i2375.

7. Thompson K, Venkatesh B, Finfer S. Sepsis and septic shock: current approaches to management. Intern Med J. 2019;49(2):160-170. doi:10.1111/imj.14199.

8. Fleischmann C, Scherag A, Adhikari NK, et al. Assessment of global incidence and mortality of hospital-treated sepsis. Current estimates and limitations. Am J Respir Crit Care Med. 2016;193(3):259-272. doi:10.1164/rccm.201504-0781OC.

9. Liu V, Escobar GJ, Greene JD, et al. Hospital deaths in patients with sepsis from 2 independent cohorts. JAMA. 2014;312(1):9092. doi:10.1001/jama.2014.5804.

10. Shankar-Hari M, Phillips GS, Levy ML, et al. Developing a new definition and assessing new clinical criteria for septic shock: for the Third International Consensus Definitions for Sepsis and Septic Shock (Sepsis-3). JAMA. 2016;315(8):775-787. doi:10.1001/jama.2016.0289.

11. Sakr Y, Jaschinski U, Wittebole $X$, et al. Sepsis in intensive care unit patients: worldwide data from the intensive care over nations audit. Open Forum Infect Dis. 2018;5(12):ofy313. doi:10.1093/ofid/ofy313.

12. Annane D, Aegerter P, Jars-Guincestre MC, Guidet B. Current epidemiology of septic shock: the CUB- Réa Network. Am J Respir Crit Care Med. 2003;168(2):165-172. doi:10.1164/ rccm.2201087.

13. Zhang $W$, Zheng $Y$, Feng $X$, Chen $M$, Kang $Y$. Systemic inflammatory response syndrome in Sepsis-3: a retrospective study. BMC Infect Dis. 2019;19(1):139. doi:10.1186/s12879019-3790-0.

14. Finfer S, Machado FR. The global epidemiology of sepsis. does it matter that we know so little? Am J Respir Crit Care Med. 2016;193(3):228-230. doi:10.1164/rccm.201510-1976ED.

15. Mbeng LO. Informal waste recovery and recycling: alleviating poverty, environmental pollution and unemployment in Douala, Cameroon. J Sci Res Rep. 2013;2(1):474-490. doi:10.9734/jsrr/2013/4436.

16. Rogers S. The Top 50 most expensive cities. Guardian. 2009 http://www.guardian.co.uk/news/datablog/2009/jul/07/globaleconomy-economics. Accessed October 9, 2019.

17. Vincent JL, Jones G, David S, Olariu E, Cadwell KK. Frequency and mortality of septic shock in Europe and North America: a systematic review and meta-analysis. Crit Care. 2019;23(1):196. doi:10.1186/s13054-019-2478-6

18. Singer M, Deutschman CS, Seymour CW, et al. The third international consensus definitions for sepsis and septic shock (Sepsis-3). JAMA. 2016;315(8):801-810. doi:10.1001/ jama.2016.0287

19. Quenot JP, Binquet C, Kara F, et al. The epidemiology of septic shock in French intensive care units: the prospective multicenter cohort EPISS study. Crit Care. 2013;17(2):R65. doi:10.1186/cc12598.

20. Ranieri VM, Thompson BT, Barie PS, et al. Drotrecogin alfa (activated) in adults with septic shock. N Engl J Med. 2012;366(22):2055-2064. doi:10.1056/NEJMoa1202290.

21. Boussekey N, Cantrel J, Dorchin Debrabant L, etal.Epidemiology, prognosis, and evolution of management of septic shock in a French intensive care unit: a five years survey. Crit Care Res Pract. 2010;2010:436427. doi:10.1155/2010/436427.

22. Baharoon S, Telmesani A, Tamim H, et al. Community- versus nosocomial-acquired severe sepsis and septic shock in patients admitted to a tertiary intensive care in Saudi Arabia, etiology and outcome. J Infect Public Health. 2015;8(5):418-424. doi:10.1016/j.jiph.2014.12.003

23. Vincent JL, de Mendonca A, Cantraine F, et al. Use of the SOFA score to assess the incidence of organ dysfunction/failure in intensive care units: results of a multicenter, prospective study. Working group on "sepsis-related problems" of the European Society of Intensive Care Medicine. Crit Care Med. 1998;26(11):1793-1800. doi:10.1097/00003246-19981100000016.

24. Vincent JL, Sakr Y, Sprung CL, et al. Sepsis in European intensive care units: results of the SOAP study. Crit Care Med. 2006;34(2):344-353. doi:10.1097/01. ccm.0000194725.48928.3a

25. Sakr Y, Elia C, Mascia L, et al. Epidemiology and outcome of sepsis syndromes in Italian ICUs: a muticentre, observational cohort study in the region of Piedmont. Minerva Anestesiol. 2013;79(9):993-1002.

26. Wynn JL, Wong HR. Pathophysiology and treatment of septic shock in neonates. Clin Perinatol. 2010;37(2):439-479. doi:10.1016/j.clp.2010.04.002

27. Alalawi MSM, Aljabran HAM, Alkhamri AM, et al. Glasgow Coma Scale in Anticipation of Sepsis and Septic Shock: Review Article. Egypt J Hosp Med. 2017;69(6):2663-2666. doi:10.12816/0042245

28. Knaus WA, Draper EA, Wagner DP, Zimmerman JE. APACHE II: a severity of disease classification system. Crit Care Med. 
1985;13(10):818-829. doi:10.1097/00003246-19851000000009.

29. Eidelman LA, Putterman D, Putterman C, Sprung CL. The spectrum of septic encephalopathy. Definitions, etiologies, and mortalities. JAMA. 1996;275(6):470-473. doi:10.1001/ jama.1996.03530300054040.

30. Dellinger RP, Levy MM, Rhodes A, et al. Surviving sepsis campaign: international guidelines for management of severe sepsis and septic shock: 2012. Crit Care Med. 2013;41(2):580637. doi:10.1097/CCM.0b013e31827e83af.

31. Dünser MW, Takala J, Ulmer $\mathrm{H}$, et al. Arterial blood pressure during early sepsis and outcome. Intensive Care Med. 2009;35(7):1225-1233. doi:10.1007/s00134-009-1427-2.

32. Strandgaard S, Olesen J, Skinhoj E, Lassen NA. Autoregulation of brain circulation in severe arterial hypertension. $\mathrm{Br}$ Med $\mathrm{J}$. 1973;1(5852):507-510. doi:10.1136/bmj.1.5852.507.

33. Carlucci A, Richard JC, Wysocki M, Lepage E, Brochard L. Noninvasive versus conventional mechanical ventilation. An epidemiologic survey. Am J Respir Crit Care Med. 2001;163(4):874-880. doi:10.1164/ajrccm.163.4.2006027.

34. Namendys-Silva SA, Hernández-Garay M, Rivero-Sigarroa E, Herrera-Gómez A. Ventilator-associated pneumonia and septic shock in emergency colorectal procedures in elderly patients. Arch Surg. 2010;145(6):602. doi:10.1001/archsurg.2010.73.

35. Kumar A, Roberts D, Wood KE, et al. Duration of hypotension before initiation of effective antimicrobial therapy is the critical determinant of survival in human septic shock. Crit Care Med. 2006;34(6):1589-1596. doi:10.1097/01. ccm.0000217961.75225.e9.

36. Gaieski DF, Mikkelsen ME, Band RA, et al. Impact of time to antibiotics on survival in patients with severe sepsis or septic shock in whom early goal-directed therapy was initiated in the emergency department. Crit Care Med. 2010;38(4):1045-
1053. doi:10.1097/CCM.0b013e3181cc4824.

37. Dellinger RP, Carlet JM, Masur H, et al. Surviving Sepsis Campaign guidelines for management of severe sepsis and septic shock. Crit Care Med. 2004;32(3):858-873. doi:10.1097/01.CCM.0000117317.18092.E4.

38. Sartelli M, Kluger $Y$, Ansaloni $L$, et al. Raising concerns about the Sepsis-3 definitions. World J Emerg Surg. 2018;13:6. doi:10.1186/s13017-018-0165-6.

39. Jung YT, Jeon J, Park JY, Kim MJ, Lee SH, Lee JG. Addition of lactic acid levels improves the accuracy of quick sequential organ failure assessment in predicting mortality in surgical patients with complicated intra-abdominal infections: a retrospective study. World J Emerg Surg. 2018;13:14. doi:10.1186/s13017018-0173-6.

40. Kashyap R, Singh TD, Rayes H, et al. Association of septic shock definitions and standardized mortality ratio in a contemporary cohort of critically ill patients. J Crit Care. 2019;50:269-274. doi:10.1016/j.jcrc.2019.01.005.

41. Carneiro AH, Póvoa P, Gomes JA. Dear Sepsis-3, we are sorry to say that we don't like you. Rev Bras Ter Intensiva. 2017;29(1):48.doi:10.5935/0103-507x.20170002.

42. Liu ZM, Chen J, Kou Q, et al. Terlipressin versus norepinephrine as infusion in patients with septic shock: a multicentre, randomised, double-blinded trial. Intensive Care Med. 2018;44(11):1816-1825. doi:10.1007/s00134-018-5267-9.

43. Díaz LE, Montero A, Gonzalez-Gross M, Vallejo Al, Romeo J, Marcos A. Influence of alcohol consumption on immunological status: a review. Eur J Clin Nutr. 2002;56 Suppl 3:S50-53. doi:10.1038/sj.ejcn.1601486.

44. von Dossow V, Schilling C, Beller S, et al. Altered immune parameters in chronic alcoholic patients at the onset of infection and of septic shock. Crit Care. 2004;8(5):R312-321. doi:10.1186/cc2911. 